\title{
Evaluation and management of amenorrhea related to congenital sex hormonal disorders
}

\author{
Ju Young Yoon, MD, \\ Chong Kun Cheon, MD, PhD
}

Department of Pediatrics, Pusan National University Children's Hospital, Yangsan, Korea
Received: 17 September, 2019

Accepted: 24 September, 2019

Address for correspondence:

Chong Kun Cheon, MD, PhD

Division of Pediatric Endocrinology,

Department of Pediatrics, Pusan

National University Children's Hospi-

tal, Pusan National University School

of Medicine, Geumo-ro 20, Yangsan

50612, Korea

Tel: $+82-55-360-3158$

Fax: +82-55-360-2181

E-mail: chongkun@pusan.ac.kr

http://orcid.org/0000-0002-8609-

5826
Primary amenorrhea is a symptom with a substantial list of underlying etiologies which presents in adolescence, although some conditions are diagnosed in childhood. Primary amenorrhea is defined as not having menarche until 15 years of age (or 13 years with secondary sex characteristics). Various etiologies of primary amenorrhea include outflow tract obstructions, gonadal dysgenesis, abnormalities of the central nervous system, various endocrine diseases, chronic illnesses, psychologic problems, and constitutional delay of puberty. The management of primary amenorrhea may vary considerably depending on the patient and the specific diagnosis. In this article, the various causes, evaluation, and management of primary amenorrhea are reviewed with special emphasis on congenital sex hormonal disorders.

Keywords: Primary amenorrhea, Evaluation, Management, Adolescent

\section{Introduction}

Amenorrhea is defined by the transient or permanent absence of menstrual flow. Amenorrhea can be divided into primary and secondary presentations. Primary amenorrhea is diagnosed when there is no menarche by 13 years of age in those without development of secondary sexual characteristics, or by 15 years of age in those with secondary sexual characteristics. ${ }^{1)}$ Secondary amenorrhea is defined as discontinuation of previously regular menses for 3 months or previously irregular menses for 6 months. ${ }^{2)}$ The prevalence of primary amenorrhea is less than $0.1 \%$, and secondary amenorrhea is more common with an incidence of about $4.0 \%{ }^{3,4)}$

Primary amenorrhea can result from many different underlying conditions. According to the etiology, amenorrhea can be categorized as: outflow tract abnormalities, primary ovarian insufficiency, hypothalamic or pituitary disorders, other endocrine gland disorders such as thyroid or adrenal gland disorders, and other causes (Table 1). In a previous study, the most common cause of primary amenorrhea was reported as gonadal dysgenesis, including Turner syndrome (43\%), followed by Müllerian agenesis (15\%) and constitutional delay of puberty $(14 \%)^{6}{ }^{6}$

Regarding various etiologies, it is important to evaluate amenorrhea carefully not to miss the underlying pathology. In this article, differential diagnoses and management of primary amenorrhea are reviewed with special emphasis on congenital sex hormonal disorders.

\section{Evalution}

Traditionally, clinicians conduct history taking, physical examinations, endocrine tests, and radiological imaging to evaluate primary amenorrhea. 


\section{History}

History taking about the possibility of pregnancy, breastfeeding history, eating and exercise habits, psychosocial stressors

Table 1. Causes of primary amenorrhea

\begin{tabular}{l} 
Anomalies of the outflow tract \\
Imperforate hymen \\
Transverse vaginal septum \\
Müllerian agenesis \\
Receptor abnormalities and enzyme deficiencies \\
Androgen insensitivity syndrome \\
5-Alpha-reductase deficiency \\
17-Alpha-hydroxylase/17,20-lyase deficiency \\
P450 oxidoreductase deficiency \\
Gonadal dysgenesis \\
Turner syndrome \\
46,XX gonadal dysgenesis \\
Swyer syndrome \\
Central anomalies \\
Hyperprolactinemia \\
Empty Sella Syndrome \\
Functional Hypothalamic Amenorrhea \\
Kallmann Syndrome \\
Craniopharyngiomas \\
Cranial Radiation \\
Other endocrine disorders \\
Polycystic ovary syndrome \\
Thyroid diseases \\
Adrenal diseases (congenital adrenal hyperplasia, adrenal tumors) \\
Cushing syndrome \\
Diabetes mellitus \\
Constitutional delay of growth and puberty \\
\hline
\end{tabular}

(e.g., perfectionist behaviors), changes in body weight, fractures, medication, chronic illness, and onset age of second sexual characteristics development should be performed (Table 2, Fig. 1). ${ }^{5}$ History of galactorrhea suggests excess prolactin which can be caused by hypothalamic or pituitary diseases or by drugs, such as metoclopramide and antipsychotic drugs. Headaches or visual field defects also can indicate underlying hypothalamic or pituitary disease." A family history should be investigated including the age of menarche of the patient's mother and siblings.

\section{Physical examination}

Clinicians should investigate changes in growth parameters such as height, weight, and body mass index (Table 2). Breast development indicates that an adequate amount of circulating estrogen exists. ${ }^{5)}$

Physical examination (or ultrasonography if needed) should be performed to investigate the presence of the uterus (Fig. 1). In addition, the vagina and cervix should be examined for anatomic abnormalities. A vaginal exam can determine the presence of outflow tract obstruction or Müllerian agenesis. ${ }^{8)}$ Acne or hirsutism suggests polycystic ovary syndrome (PCOS), while virilization can imply a more severe androgen excess due to an androgen-secreting ovarian or adrenal tumor or 5-alphareductase deficiency (5a-RD2). ${ }^{9)}$ Dysmorphism such as the presence of a webbed neck or shield chest may suggest Turner syndrome.

\section{Laboratory and other testing}

A pregnancy test is recommended as a first step in evaluating

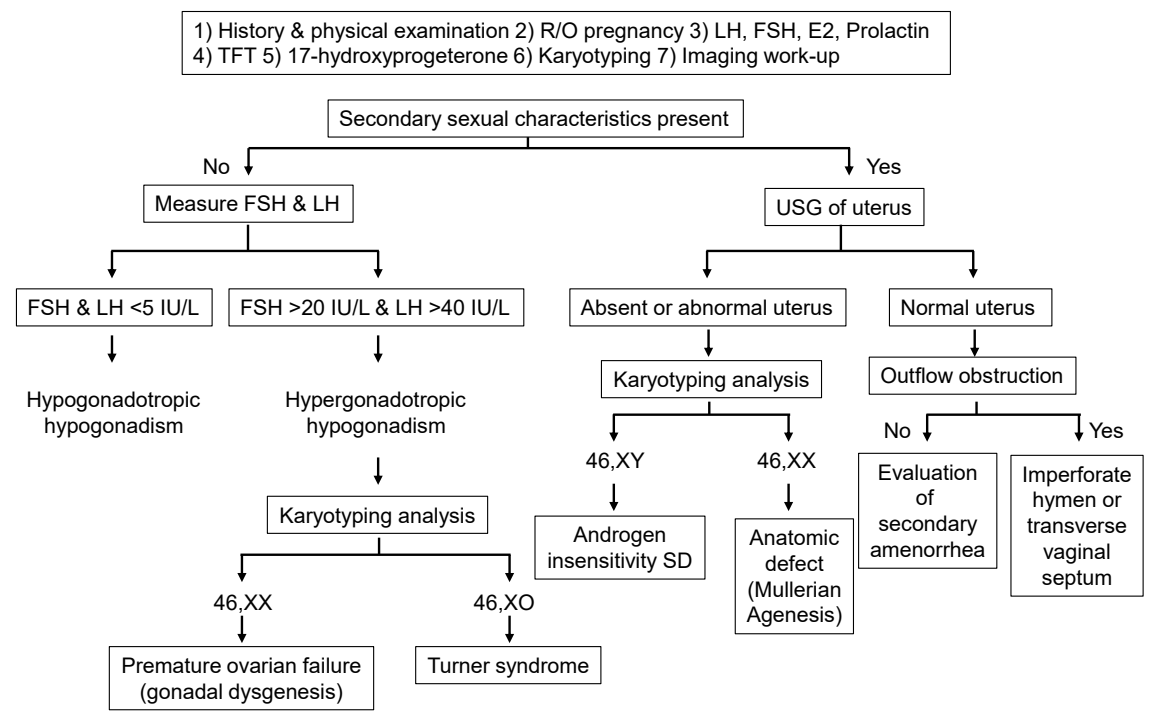

Fig. 1. Diagram aiding in the evaluations of primary amenorrhea. LH, luteinizing hormone; FSH, follicle stimulating hormone; TFT, thyroid function test; USG, ultrasonography; SD, syndrome, 
any girls with primary amenorrhea. ${ }^{10)}$ Serum levels of follicle stimulating hormone (FSH), luteinizing hormone, prolactin, and thyroid-stimulating hormone should be measured to rule out endocrine causes of amenorrhea (Table 3). ${ }^{5}$ If there are symptoms and signs of hyperandrogenism, serum free and total testosterone, and dehydroepiandrosterone sulfate levels should be measured. A hormonal challenge can be used to determine the presence of functioning anatomy and adequate endometrial estrogen exposure. ${ }^{5)}$ If a central lesion is suspected, magnetic resonance imaging (MRI) of the brain should be considered. Furthermore, pelvic ultrasonography or MRI can identify structural anomalies of the outflow tract. ${ }^{10)}$ In patients with short stature and primary amenorrhea, karyotyping should be considered to rule out a syndromic disorder such as Turner syndrome. ${ }^{8)}$ Moreover, 46, XY disorders of sexual development (DSD) can also present with primary amenorrhea with normal external female genitalia. Actually, the genetic causes of DSD are highly heterogeneous thereby posing a diagnostic challenge. Baxter et al. ${ }^{11)}$ reported whole exome sequencing followed by analysis of selected DSD genes as having a diagnostic yield of $22.5 \%$ in patients with $46, \mathrm{XY}$ DSD. A more recent study revealed a relatively higher yield by a targeted panel sequencing approach, in which a genetic diagnosis was made in $38.1 \%{ }^{12)}$ Considering the diagnostic potential of a high-throughput approach, next-generation sequencing (NGS) panels for DSD could be used in practice to uncover the underlying genetic causes of primary amenorrhea.

\section{Table 2. Findings in the evaluation of amenorrhea}

\begin{tabular}{|c|c|}
\hline Findings & Associations \\
\hline \multicolumn{2}{|l|}{ History } \\
\hline Chemotherapy or radiation & Impairment of specific organ or structure, (e.g., brain, pituitary, ovary) \\
\hline Family history of early or delayed menarche & Constitutional delay of puberty \\
\hline Galactorrhea & Pituitary tumor \\
\hline Hirsutism, acne & Hyperandrogenism, PCOS, ovarian or adrenal tumor, $\mathrm{CAH}$, Cushing syndrome \\
\hline Illicit or prescription drug use & Multiple associations, consider effect on prolactin \\
\hline Loss of smell (anosmia) & Kallman syndrome (GnRH deficiency) \\
\hline Menarche and menstrual history & Primary vs. secondary amenorrhea \\
\hline Sexual activity & Pregnancy \\
\hline Significant headaches or vision changes & Central nervous system tumor, empty sella syndrome \\
\hline $\begin{array}{l}\text { Temperature intolerance, palpitations, diarrhea, } \\
\text { constipation, tremor, depression, skin changes }\end{array}$ & Thyroid disease \\
\hline Vasomotor symptoms (e.g., hot flashes or night sweats) & Primary ovarian insufficiency, natural menopause \\
\hline $\begin{array}{l}\text { Weight loss, excessive exercise, poor nutrition, } \\
\text { psychosocial distress, diets }\end{array}$ & Functional hypothalamic amenorrhea \\
\hline Hypertension and hirsutism & 17-hydroxylase/17,20-lyase deficiency \\
\hline \multicolumn{2}{|l|}{ Physical examination } \\
\hline Abnormal thyroid examination & Thyroid disorder \\
\hline Acanthosis nigricans or skin tags & Hyperinsulinemia (PCOS) \\
\hline Anthropomorphic measurements; growth charts & Multiple associations; Turner syndrome, constitutional delay of puberty \\
\hline Body mass index & High: PCOS \\
\hline \multicolumn{2}{|l|}{ Low: Functional hypothalamic amenorrhea } \\
\hline Bradycardia & Functional hypothalamic amenorrhea (e.g., anorexia nervosa) \\
\hline Breast development (normal progression) & Presence of circulating estrogen ${ }^{*}$ \\
\hline $\begin{array}{l}\text { Dysmorphic features (e.g., webbed neck, } \\
\text { short stature, low hairline) }\end{array}$ & Turner syndrome \\
\hline $\begin{array}{l}\text { Male pattern baldness, increased facial hair, acne } \\
\text { Pelvic examination }\end{array}$ & Hyperandrogenism, PCOS, ovarian or adrenal tumor, nonclassic CAH, Cushing syndrome \\
\hline Absence or abnormalities of cervix or uterus & Rare congenital causes including Müllerian agenesis or androgen insensitivity syndrome \\
\hline Clitoromegaly & Androgen-secreting tumor; $\mathrm{CAH}$; 5a-reductase deficiency \\
\hline Presence of transverse septum or imperforate hymen & Outflow tract obstruction \\
\hline Reddened or thin vaginal mucosa & Decreased endogenous estrogen \\
\hline Sexual maturity rating abnormal & Turner syndrome, constitutional delay of puberty, rare causes \\
\hline Striae, buffalo hump, central obesity, hypertension & Cushing syndrome \\
\hline
\end{tabular}

PCOS, polycystic ovary syndrome; $\mathrm{CAH}$, congenital adrenal hyperplasia; $\mathrm{GnRH}$, gonadotropin-releasing hormone.

*Absence of breast buds may not indicate nonfunctioning ovaries or future functionality.

Adapted from Klein et al., Am Fam Physician 2019;100:39-48, with permission of American Academy of Family Physicians. ${ }^{5)}$ 
Table 3. Laboratory and radiographic testing in the evaluation of amenorrhea

\begin{tabular}{|c|c|}
\hline Findings & Associations \\
\hline \multicolumn{2}{|l|}{ Laboratory testing (refer to local reference values) } \\
\hline 17-hydroxyprogesterone level (collected at 8:00 AM) & High: nonclassic $\mathrm{CAH}$ \\
\hline \multirow[t]{2}{*}{ Anti-Müllerian hormone } & High: Functional hypothalamic amenorrhea, PCOS \\
\hline & Low: Primary ovarian insufficiency \\
\hline Complete blood count and metabolic panel & $\begin{array}{l}\text { Abnormal: chronic disease (e.g., elevated liver enzymes in functional hypothalamic } \\
\text { amenorrhea) }\end{array}$ \\
\hline Estradiol & Low: Poor endogenous estrogen production (suggestive of poor current ovarian function) \\
\hline \multirow[t]{3}{*}{ Follicle stimulating hormone and luteinizing hormone } & High: primary ovarian insufficiency; Turner syndrome, FSH receptor mutation \\
\hline & Low: functional hypothalamic amenorrhea \\
\hline & Normal: PCOS; intrauterine adhesions; multiple others \\
\hline Free and total T, DHEA-S & High: hyperandrogenism, PCOS, ovarian or adrenal tumor, $\mathrm{CAH}$, Cushing syndrome \\
\hline T/DHT ratio (normal <30:1) & High: 5-a-reductase deficiency \\
\hline At puberty, serum $L H$, and $T$ & High: androgen insensitivity syndrome \\
\hline Karyotype & Abnormal: turner syndrome, rare chromosomal disorders \\
\hline Prolactin & High: pituitary adenoma, medications, hypothyroidism, other neoplasm \\
\hline \multirow[t]{2}{*}{ Thyroid-stimulating hormone } & High: hypothyroidism \\
\hline & Low: hyperthyroidism \\
\hline \multicolumn{2}{|l|}{ Radiographic testing } \\
\hline Dual-energy X-ray absorptiometry & Evaluation of fracture risk \\
\hline MRI of the adrenal glands & Androgen-secreting adrenal tumor \\
\hline MRI of the brain (including sella) & Tumor (e.g., microadenoma) \\
\hline Pelvic organ ultrasonography or MRI & $\begin{array}{l}\text { Morphology of pelvic organs, polycystic ovarian morphology, androgen-secreting ovarian } \\
\text { tumor }\end{array}$ \\
\hline
\end{tabular}

$\overline{\mathrm{CAH}}$, congenital adrenal hyperplasia; PCOS, polycystic ovary syndrome; FSH, follicle stimulating hormone; DHEA-S, dehydroepiandrosterone sulfate; DHT, dihysrotestosterone; LH, luteinizing hormone; MRI, magnetic resonance imaging; T, testosterone.

Modified from Klein et al., Am Fam Physician 2019;100:39-48, with permission of American Academy of Family Physicians. ${ }^{5)}$

\section{Anomalies of the outflow tract}

\section{Imperforate hymen}

An imperforate hymen usually presents as a bluish bulging mass due to hematocolpos at the entrance to the vagina. The treatment is simple resection to allow for drainage of menstrual blood, and then the hymen is excised. After treatment, patients can have normal menstrual function.

\section{Transverse vaginal septum}

A transverse vaginal septum is caused by persistence of the vaginal plate after it meets the Müllerian tract. ${ }^{13)}$ Septa can lie anywhere along the length of the vaginal cavity. The most common location is high in the vaginal cavity. ${ }^{14)}$ It is a rare anomaly, found in 1:2100 to 1:72,000 females. ${ }^{15)}$ The physical exam reveals a shortened blind vaginal pouch. Symptoms include dysmenorrhea and/or dyspareunia. The treatment is surgical resection.

\section{Müllerian agenesis}

Müllerian agenesis, also known as vaginal agenesis or MayerRokitansky-Küster-Hauser (MRKH) syndrome, is defined by congenital absence of the vagina. It is most commonly associated with uterine agenesis, but, $7 \%$ to $10 \%$ of patients have an obstructed or rudimentary uterus. ${ }^{15)}$

Patients will typically have no complaint other than amenorrhea. If the patient complains of cyclic pain, MRI is useful in detecting endometrium in uterine remnants. Remaining active endometrial tissue may require surgical removal. Patients have normal female external genitalia, ovaries, and hormonal patterns. Patients can also have renal and skeletal anomalies. MRKH syndrome accounts for $20 \%$ of the causes of primary amenorrhea ${ }^{16)}$ in Koreans.

\section{Gonadal dysgenesis}

Gonadal dysgenesis refers to incomplete or defective formation of the gonads, which is the most common cause of primary amenorrhea $(30 \%-40 \%) .{ }^{13)}$ These women have decreased estradiol and an elevated FSH level. There are many types of gonadal dysgenesis: pure, partial, and mixed. Pure gonadal dysgenesis patients have streak gonads with karyotypes such as 45,XO (Turner syndrome), 46,XX, or 46,XY (Swyer syndrome). Patients with partial gonadal dysgenesis have bilateral dysgenic gonads, and mixed gonadal dysgenesis present with 1 streak and 1 dysgenic gonad. 


\section{Turner syndrome}

About two-thirds of cases of gonadal dysgenesis are caused by Turner syndrome. ${ }^{17)}$ In Turner syndrome, while the ovarian germ cells undergo normal migration and mitosis, normal meiosis does not occur, leading to rapid loss of oocytes. About 70\%-80\% have no spontaneous pubertal development and $90 \%$ experience primary amenorrhea. ${ }^{18)}$ Estrogen and cyclic progesterone replacement is required for induction of pubertal development from about 11 years of age. Unopposed low dose estrogen should be started first, as progesterone will cause misshapen tubular breasts. Heterologous in vitro fertilization-embryo transfer, using oocyte donation, is the most used reproductive technique and it represents the only way to become pregnant. At the age of 13-14 years, girls with Turner syndrome should be counselled about fertility options and, in those with mosaic karyotype and spontaneous puberty in the absence of any elevation in FSH or reduction in AMH, the discussion should include cryopreservation. ${ }^{19,20)}$ Given the concerns with ovarian cryopreservation in Turner syndrome, an algorithmic approach to decision-making for fertility preservation in females with Turner syndrome was developed. ${ }^{21)}$

\section{46,XX gonadal dysgenesis}

46 , XX gonadal dysgenesis is caused by defects in autosomal genes. Patients with 46,XX gonadal dysgenesis present with amenorrhea and absent secondary sex characteristics, but otherwise have a normal phenotype. ${ }^{13)}$ Patients have a normal 46,XX karyotype and streak gonads. ${ }^{22)}$ There are syndromic forms accompanying sensorineural hearing loss (Perrault syndrome). hormone replacement therapy (HRT) with estrogen and cyclic progesterone is required.

\section{46,XY gonadal dysgenesis (Swyer syndrome)}

46,XY gonadal dysgenesis is also called Swyer syndrome. About $10 \%$ to $20 \%$ of these cases are caused by SRY gene mutation. ${ }^{13)}$ Patients have streak gonads or nonfunctional testicular tissue.

The gonads produce neither AMH nor androgens. As a result, they have normal female internal and external genitalia. They are phenotypically female, and present with primary amenorrhea and delayed secondary sex characteristics. Gonadectomy is required due to a high risk of malignant transformation. Patients also receive HRT for induction of puberty. Pregnancy is possible with appropriate HRT and assisted reproductive technology. ${ }^{23)}$

\section{Central anomalies}

\section{Pituitary disorders}

Hyperprolactinemia or decreased gonadotropin due to disturbance of pituitary function can cause amenorrhea.

\section{1) Hyperprolactinemia}

Hyperprolactinemia can be caused by multiple causes (prolactinoma, diseases involving the hypothalamus-pituitary, medications, systemic illnesses, etc.) and is a common cause of amenorrhea.

Hyperprolactinemia accounts for $4 \%$ of the causes of primary amenorrhea in Koreans. ${ }^{16)}$ Patients with a prolactinoma may have galactorrhea or ocular headaches. ${ }^{13)}$ Patients with a macroadenoma may also present with symptoms of pituitary stalk compression such as headaches, visual disturbances, poor growth, and diabetes insipidus. ${ }^{22)}$ Dopamine agonists are used for the treatment of hyperprolactinemia. They decrease prolactin, resume menses, increase fertility, and increase absorption of calcium to bones. Combined oral contraceptives can be used to restore menstrual regularity.

\section{2) Empty sella syndrome}

Empty sella syndrome is defined by the shrinkage or flattening of the pituitary gland. This disorder is due to congenital defects in the sellar diaphragm in which the sella turcica is filled with cerebrospinal fluid instead of the normal pituitary gland. This condition can cause pituitary stalk compression, disrupting the hypothalamic-pituitary-ovarian axis. ${ }^{13)}$

\section{Hypothalamic disorders}

Hypothalamic disorders can cause hypogonadotropic hypogonadism. Etiologies include craniopharyngioma, cranial irradiation, functional hypothalamic amenorrhea, Kallmann syndrome, etc.

\section{1) Craniopharyngiomas}

Craniopharyngiomas account for 3\% of intracranial neoplasms and $1 \%$ of primary amenorrhea. ${ }^{24)}$

Most present at ages of 6 to 14 years with symptoms such as headaches, visual disturbances, delayed development, poor growth, and diabetes insipidus. ${ }^{22)}$ Amenorrhea is caused by compression of the hypothalamus and pituitary. Treatment is surgical resection, but recurrence is common. The addition of radiation and microsurgical techniques can decrease the recurrence rate. $^{24)}$

\section{2) Functional hypothalamic amenorrhea}

Functional hypothalamic amenorrhea is caused by disorders that inhibit pulsatile release of $\mathrm{GnRH}$, such as eating disorders, exercise, malnutrition, and stress. They are usually causes of secondary amenorrhea but can cause primary amenorrhea. Amenorrhea from these disorders, to some extent, is explained by a stress-induced increase in cortisol levels due to activation of corticotrophin-releasing hormone. ${ }^{13)}$

3) Kallmann syndrome

Kallmann syndrome is an X-linked disorder, which is characterized by delayed puberty and anosmia. Kallmann synd- 
rome results from mutations that cause a defect in migration of the GnRH neurons and the olfactory neurons. ${ }^{22)}$ Treatment includes sex hormone replacement with estrogen and progesterone. Gonadotropin or pulsatile GnRH therapy can also be used to induce fertility. ${ }^{25)}$

4) Other central nervous system causes

Amenorrhea can be caused by hypothalamic-pituitary axis damage through inflammation, ischemia, infiltration, infection, irradiation, or trauma.

\section{Receptor abnormalities and enzyme deficiencies}

\section{Androgen insensitivity syndrome}

Androgen insensitivity syndrome (AIS) is caused by defective function of the androgen receptor. An inactivating mutation of the gene encoding for the androgen receptor leads to endorgan insensitivity to androgens. Androgen resistance that results in complete AIS is characterized by XY sex reversal with a normal female phenotype. With residual androgen receptor activity, partial AIS results in a variable phenotype. The majority of 46,XY DSD cases are due to AIS with elevated testosterone levels. Anti-Müllerian hormone (AMH) is normally secreted, resulting in a short blind vagina. There is breast development due to peripheral conversion of androgens to estrogen. ${ }^{13)}$ Amenorrhea is the most clinically observed sign of AIS. Kwon et al. ${ }^{16)}$ reported AIS in $8.3 \%$ among 132 patients with primary amenorrhea in Korea. Removal of the gonads owing to a $5 \%$ to $10 \%$ incidence of malignancy is required. ${ }^{13)}$ However, gonadectomy should be recommended after completion of puberty because tumor incidence is very rare in patients under 20 years of age. ${ }^{26)}$ After gonadectomy, hormone replacement therapy is required in order to maintain secondary sexual characteristics, bone and cardiovascular health and to promote general wellbeing and sexual function. ${ }^{27}$

\section{5-Alpha-reductase deficiency}

5-Alpha-reductase deficiency can result in primary amenorrhea in a $46, X Y$ subject. At birth, these patients may have ambiguous genitalia due to an inability to convert testosterone to its more potent metabolite dihydrotestosterone (DHT). Twothirds of patients with $5 a-$ RD2 who were initially assigned female gender and all who were assigned male gender, live as males. ${ }^{28)}$ During puberty, they can exhibit virilization due to the normal peripubertal increase in testosterone secretion without breast development. ${ }^{29)}$ However, these individuals do not undergo enlargement of the male external genitalia which is DHT-dependent. ${ }^{30)}$ Management decisions are based on multiple factors including reproductive anatomy, DSD etiology, parental/cultural factors, and most importantly, outcome. ${ }^{31)}$ The size of the penis and its potential to develop at puberty into a sexually functional penis are among the most important concerns when one is considering assignment of male sex. ${ }^{32)}$ If the patient is to be raised as a male, surgical correction should be performed. Standard surgical repair operations such as chordee correction, orchidopexia, and urethral reconstruction are done between 6 and 18 months of age, usually in one stage as an outpatient procedure. ${ }^{28)}$ Prior to surgery, treatment with androgens is required to increase phallic length and promote hypospadia repair. Meanwhile, if the child is raised as a female, surgical correction of the external genitalia should be considered and gonadal tissue should be removed early to prevent masculinization before puberty. ${ }^{33)}$ Feminizing genital surgery includes reconstruction of the external genitalia and providing an adequate vaginal opening into the perineum, with early separation of the vagina and urethra. ${ }^{28,34)}$ During the teenage years, vaginoplasty should be considered. ${ }^{28)}$ Cyclic hormonal therapy at puberty for the development of secondary sexual characteristics is required.

\section{FSH receptor mutation}

Inactivating mutations of the FSH receptor (FSHR) can cause amenorrhea due to ovarian failure. ${ }^{35)}$ In individuals with FSH resistance, follicular maturation is impaired, although most patients show small $(3-5 \mathrm{~mm})$ follicles by transvaginal ultrasound and follicular arrest at the small antral stage. ${ }^{36,37)}$ As a result, inactivating mutations of FSHR cause hypergonadotropic hypoestrogenic amenorrhea with elevated FSH and low estrogen levels. In patients with a FSH receptor mutation, AMH is secreted by small growing follicles, resulting in detectable values which are likely varying with the mutation severity and follicular arrest stage ${ }^{38)}$ Because FSHR mutations are detected in $<1 \%$ of patients with primary ovarian failure, ${ }^{39)}$ a candidate gene approach is far less efficient than whole exome sequencing (WES) for uncovering the etiology of primary amenorrhea. WES-assisted diagnosis allows for treatments aimed at the underlying molecular etiology of disease. Analysis of genotypephenotype association and in vitro functional characterization of inactivating mutations of FSHR have led to important information about the contribution of the mutated residues and the corresponding region in hormone receptor interaction and signal transduction. ${ }^{40)}$ Therefore, research on pharmacological and assisted reproductive treatments aimed at the disrupted FSHR is necessary to provide patients with FSH resistance personalized medicine.

\section{Polycystic ovary syndrome}

PCOS is characterized by ovulatory dysfunction, biochemical or clinical androgen access, and polycystic ovaries. ${ }^{8)}$ FSHR is known to play a role in the pathophysiology of the disease. Polymorphisms of FSHR are known to alter the response to exogenous FSH or the risk of having PCOS. ${ }^{41)}$ In addition, genome wide association studies have found that variants in the FSH- $\beta$ gene and the LH receptor gene (LHCGR) were also 
found by genome wide association study. ${ }^{42)}$

The American Society of Reproductive Medicine Practice Committee reported that 1 of the 4 most common cause of amenorrhea was PCOS. ${ }^{43)}$ Prescribing combined oral contraceptives is the first-line therapy for menstrual abnormalities, hirsutism, and acne. Oral contraceptives can also provide protection from endometrial cancer caused by unopposed estrogen secretion. ${ }^{44,45}$ Metformin is recommended for patients with impaired glucose tolerance and those in whom lifestyle modifications are unsuccessful, or for those with contraindications to applicable contraceptives. ${ }^{44)}$ For patients with PCOS and infertility, letrozole is the treatment of choice, because higher rates of ovulation, pregnancy, and live birth were reported with letrozole than clomiphene. ${ }^{44)}$

\section{Nonclassic congenital adrenal hyperplasia}

Nonclassic congenital adrenal hyperplasia (NCAH) is a common cause of hyperandrogenic amenorrhea. NCAH due to P450c21 (21-hydroxylase) deficiency is a common autosomal recessive disorder due to mutations in the CYP21A2 gene. The clinical consequences of NCAH expand from infancy, i.e., accelerated growth, to adolescence and adulthood, i.e., premature pubarche, cutaneous symptoms, hirsutism, amenorrhea, chronic anovulation, and infertility. ${ }^{46)}$ In a study of 220 adolescents, menstrual irregularities (56\%) or even primary amenorrhea (9\%) were the presenting sign of $\mathrm{NCAH}^{47)}$ Despite the adrenal and ovarian androgen excess, the majority of women with NCAH will conceive spontaneously. ${ }^{48)}$ Between $10 \%$ and $30 \%$ of NCAH women of reproductive age complain of infertility. ${ }^{49)}$ Persistent elevated progestogen concentrations owing to excess circulating levels of progesterone and 17 hydroxyprogesterone (17-OHP) of adrenal origin may also result in an unfavorable cervical mucus and a persistent decidualized or hypo- or atrophic endometrium. ${ }^{50)}$

\section{17-hydroxylase/17,20-lyase deficiency}

This is a rare form of congenital adrenal hyperplasia, characterized by hypertension and sexual infantilism and caused by loss-of-function mutations in CYP17A1. The CYP17A1 enzyme catalyzes both steroid 17-hydroxylase and 17,20-lyase activities. 17-hydroxylase/17,20-lyase deficiency are forms of CAH that impair both adrenal and gonadal function. ${ }^{51)}$ Isolated 17,20-lyase deficiency does not significantly lead to adrenal hyperplasia and is more a form of gonadal insufficiency. Nearly 100 disease-causing mutations in 17-hydroxylase/17,20lyase deficiency have been found. Primary amenorrhea is typical in patients with complete 17-hydroxylase/17,20-lyase deficiency. Diagnosis of 17-hydroxylase/17,20-lyase deficiency is made based on the presence of hypertension, elevated DOC (>1 ng/mL [>3 nmol/L]), elevated corticosterone (>40 ng/ $\mathrm{mL}[>116 \mathrm{nmol} / \mathrm{L}])$ with low cortisol $(<5 \mu \mathrm{g} / \mathrm{dL}[<138 \mathrm{nmol} /$ $\mathrm{L}])$, androgens and estrogens, and suppressed renin. ${ }^{52,53)}$
Treatments of 17-hydroxylase/17,20-lyase deficiency include mineralocorticoid receptor antagonists (spironolactone), antihypertensive drugs (amiloride), and glucocorticoid. ${ }^{53)}$ HRT is initiated during adolescence or upon diagnosis if an adult. Surgery of the external genitalia is rarely necessary.

\section{Conclusions}

Here we provided a summary of the assessment and management of primary amenorrhea with special emphasis on congenital sex hormonal disorders. Despite traditional approaches such as careful history taking, physical exam, laboratory testing including chromosome and/or single gene analysis, and imaging work-up to evaluate primary amenorrhea, the molecular basis and pathophysiology remains unknown for some rare causes of primary amenorrhea. These rare causes may call for NGS-based methods allowing for a broad search for variants in patients with puzzling phenotypes. Treatment of primary amenorrhea may vary considerably, and rely on the patient and the specific diagnosis.

\section{Conflicts of interest}

No potential conflict of interest relevant to this article was reported.

\section{References}

1. ACOG Committee Opinion No. 651: Menstruation in girls and adolescents: using the menstrual cycle as a vital sign. Obstet Gynecol 2015;126:e143-6.

2. Klein DA, Poth MA. Amenorrhea: an approach to diagnosis and management. Am Fam Physician 2013;87:781-8.

3. Timmreck LS, Reindollar RH. Contemporary issues in primary amenorrhea. Obstet Gynecol Clin North Am 2003;30:287-302.

4. Pettersson F, Fries H, Nillius SJ. Epidemiology of secondary amenorrhea. I. Incidence and prevalence rates. Am J Obstet Gynecol 1973;117:80-6.

5. Klein DA, Paradise SL, Reeder RM. Amenorrhea: a systematic approach to diagnosis and management. Am Fam Physician 2019;100:39-48.

6. Reindollar RH, Byrd JR, McDonough PG. Delayed sexual development: a study of 252 patients. Am J Obstet Gynecol 1981;140:371-80.

7. Molitch ME. Diagnosis and treatment of pituitary adenomas: a review. JAMA 2017;317:516-24.

8. Practice Committee of American Society for Reproductive Medicine. Current evaluation of amenorrhea. Fertil Steril 2008;90(5 Suppl):S219-25.

9. Well CK, Barbieri RL. Evaluation and management of primary amenorrhea [Internet]. UpToDate; 2019 [updated 2019 Mar 21; cited 2019 Sep 8]. Available from: https://www.uptodate.com/contents/evaluation-andmanagement-of-primary-amenorrhea. 
10. Gordon CM, Ackerman KE, Berga SL, Kaplan JR, Mastorakos G, Misra M, et al. Functional hypothalamic amenorrhea: an endocrine society clinical practice guideline. J Clin Endocrinol Metab 2017;102:1413-39.

11. Baxter RM, Arboleda VA, Lee H, Barseghyan H, Adam MP, Fechner PY, et al. Exome sequencing for the diagnosis of 46,XY disorders of sex development. J Clin Endocrinol Metab 2015;100:E333-44.

12. Dong Y, Yi Y, Yao H, Yang Z, Hu H, Liu J, et al. Targeted next-generation sequencing identification of mutations in patients with disorders of sex development. BMC Med Genet 2016;17:23.

13. Marc A, Fritz MD, Leon S. Clinical gynecologic endocrinology and infertility. 8th ed. Philadelphia (PA): Lippincott Williams \& Wilkins, 2013.

14. Rock JA, Zacur HA, Dlugi AM, Jones HW Jr, TeLinde RW. Pregnancy success following surgical correction of imperforate hymen and complete transverse vaginal septum. Obstet Gynecol 1982;59:448-51.

15. Marsh CA, Grimstad FW. Primary amenorrhea: diagnosis and management. Obstet Gynecol Surv 2014;69:603-12.

16. Kwon SK, Chae HD, Lee KH, Kim SH, Kim CH, Kang BM. Causes of amenorrhea in Korea: experience of a single large center. Clin Exp Reprod Med 2014;41:29-32.

17. Hoffman BL, Schorge JO, Bradshaw KD, Halvorson LM, Schaffer JI, Corton MM. Williams gynecology. New York: McGraw-Hill Medical, 2012.

18. Oktay K, Bedoschi G, Berkowitz K, Bronson R, Kashani B, McGovern P, et al. Fertility preservation in women with Turner syndrome: a comprehensive review and practical guidelines. J Pediatr Adolesc Gynecol 2016;29:409-16.

19. Bryman I, Sylvén L, Berntorp K, Innala E, Bergström I, Hanson C, et al. Pregnancy rate and outcome in Swedish women with Turner syndrome. Fertil Steril 2011;95:250710.

20. Lucaccioni L, Wong SC, Smyth A, Lyall H, Dominiczak A, Ahmed SF,et al. Turner syndrome--issues to consider for transition to adulthood. Br Med Bull 2015;113:45-58.

21. Oktay K, Bedoschi G. Fertility preservation in girls with Turner syndrome: limitations, current success and future prospects. Fertil Steril 2019;111:1124-6.

22. Emans SJ, Goldstein DP, Laufer MR. Pediatric and adolescent gynecology. 5th ed. Philadelphia (PA): Lippincott Williams \& Wilkins, 2005.

23. Michala L, Goswami D, Creighton SM, Conway GS. Swyer syndrome: presentation and outcomes. BJOG 2008;115:737-41.

24. Larijani B, Bastanhagh MH, Pajouhi M, Kargar Shadab F, Vasigh A, Aghakhani S. Presentation and outcome of 93 cases of craniopharyngioma. Eur J Cancer Care (Engl) 2004;13:11-5.

25. Balasubramanian R, Crowley WF Jr. Isolated gonadotropinreleasing hormone $(\mathrm{GnRH})$ deficiency. In: Margaret PA, Holly HA, editors. GeneReviews. Seattle: University of Washington, 1993.

26. Chaudhry S, Tadokoro-Cuccaro R, Hannema SE, Acerini
CL, Hughes IA. Frequency of gonadal tumours in complete androgen insensitivity syndrome (CAIS): a retrospective case-series analysis. J Pediatr Urol 2017;13:498.e1-498.e6.

27. Deligeoroglou E, Athanasopoulos N, Tsimaris P, Dimopoulos KD, Vrachnis N, Creatsas G. Evaluation and management of adolescent amenorrhea. Ann N Y Acad Sci 2010;1205:23-32.

28. Houk CP, Hughes IA, Ahmed SF, Lee PA; Writing Committee for the International Intersex Consensus Conference Participants. Summary of consensus statement on intersex disorders and their management. International Intersex Consensus Conference. Pediatrics 2006;118:753-7.

29. Cheon CK. Practical approach to steroid 5alpha-reductase type 2 deficiency. Eur J Pediatr 2011;170:1-8.

30. Well CK, Barbieri RL. Causes of primary amenorrhea [Internet]. UpToDate; 2019 [updated 2017 Dec 6; cited 2019 Sep 8]. Available from: https://www.uptodate.com/ contents/causes-of-primary-amenorrhea.

31. Mieszczak J, Houk CP, Lee PA. Assignment of the sex of rearing in the neonate with a disorder of sex development. Curr Opin Pediatr 2009;21:541-7.

32. Kojima Y, Mizuno K, Nakane A, Kato T, Kohri K, Hayashi Y. Long-term physical, hormonal, and sexual outcome of males with disorders of sex development. J Pediatr Surg 2009;44:1491-6.

33. Sultan C, Paris F, Terouanne B, Balaguer P, Georget V, Poujol $\mathrm{N}$, et al. Disorders linked to insufficient androgen action in male children. Hum Reprod Update 2001;7:314-22.

34. Mendonca BB, Domenice S, Arnhold IJ, Costa EM. 46,XY disorders of sex development (DSD). Clin Endocrinol (Oxf) 2009;70:173-87.

35. Doherty E, Pakarinen P, Tiitinen A, Kiilavuori A, Huhtaniemi I, Forrest S, et al. A Novel mutation in the FSH receptor inhibiting signal transduction and causing primary ovarian failure. J Clin Endocrinol Metab 2002;87:1151-5.

36. Channing CP, Schaerf FW, Anderson LD, Tsafriri A Ovarian follicular and luteal physiology. Int Rev Physiol 1980;22:117-201.

37. Jiang X, Dias JA, He X. Structural biology of glycoprotein hormones and their receptors: insights to signaling. Mol Cell Endocrinol 2014;382:424-51.

38. Bramble MS, Goldstein EH, Lipson A, Ngun T, Eskin A, Gosschalk JE, et al. A novel follicle-stimulating hormone receptor mutation causing primary ovarian failure: a fertility application of whole exome sequencing. Hum Reprod 2016;31:905-14.

39. Persani L, Rossetti R, Cacciatore C. Genes involved in human premature ovarian failure. J Mol Endocrinol 2010; 45:257-79.

40. Desai SS, Roy BS, Mahale SD. Mutations and polymorphisms in FSH receptor: functional implications in human reproduction. Reproduction 2013;146:R235-48.

41. Laven JSE. Follicle stimulating hormone receptor (FSHR) polymorphisms and polycystic ovary syndrome (PCOS). Front Endocrinol (Lausanne) 2019;10:23.

42. McAllister JM, Legro RS, Modi BP, Strauss JF 3rd. Func- 
tional genomics of PCOS: from GWAS to molecular mechanisms. Trends Endocrinol Metab 2015;26:118-24.

43. Practice Committee of the American Society for Reproductive Medicine. Obesity and reproduction: a committee opinion. Fertil Steril 2015;104:1116-26.

44. ACOG Practice Bulletin No. 194: Polycystic Ovary Syndrome. Obstet Gynecol 2018;131:e157-71.

45. Melmed S, Casanueva FF, Hoffman AR, Kleinberg DL, Montori VM, Schlechte JA, et al. Diagnosis and treatment of hyperprolactinemia: an Endocrine Society clinical practice guideline. J Clin Endocrinol Metab 2011;96:273-88.

46. Carmina E, Dewailly D, Escobar-Morreale HF, Kelestimur F, Moran C, Oberfield S, et al. Non-classic congenital adrenal hyperplasia due to 21-hydroxylase deficiency revisited: an update with a special focus on adolescent and adult women. Hum Reprod Update 2017;23:580-99.

47. Moran C, Azziz R, Carmina E, Dewailly D, Fruzzetti F, Ibañez L, et al. 21-Hydroxylase-deficient nonclassic adrenal hyperplasia is a progressive disorder: a multicenter study. Am J Obstet Gynecol 2000;183:1468-74.

48. Moran C, Azziz R, Weintrob N, Witchel SF, Rohmer V, Dewailly D, et al. Reproductive outcome of women with 21-hydroxylase-deficient nonclassic adrenal hyperplasia. J Clin Endocrinol Metab 2006;91:3451-6.

49. Bidet M, Bellanné-Chantelot C, Galand-Portier MB, Golmard JL, Tardy V, Morel Y, et al. Fertility in women with nonclassical congenital adrenal hyperplasia due to 21-hydroxylase deficiency. J Clin Endocrinol Metab 2010;95:1182-90.

50. Reichman DE, White PC, New MI, Rosenwaks Z. Fertility in patients with congenital adrenal hyperplasia. Fertil Steril 2014;101:301-9.

51. Miller WL, Auchus RJ. The molecular biology, biochemistry, and physiology of human steroidogenesis and its disorders. Endocr Rev 2011;32:81-151.

52. Griffing GT, Wilson TE, Holbrook MM, Dale SL, Jackson TK, Ullrich I, et al. Plasma and urinary 19-nordeoxycorticosterone in 17 alpha-hydroxylase deficiency syndrome. J Clin Endocrinol Metab 1984;59:1011-5.

53. Martin RM, Lin CJ, Costa EM, de Oliveira ML, Carrilho A, Villar H, et al. P450c17 deficiency in Brazilian patients: biochemical diagnosis through progesterone levels confirmed by CYP17 genotyping. J Clin Endocrinol Metab 2003;88:5739-46. 